\title{
$\mathrm{SiO}_{2}$ beads decorated with $\mathrm{SrO}$ nanoparticles for
}

\section{biodiesel production from waste cooking oil using}

\section{microwave irradiation}

\author{
Alex Tangy, ${ }^{\mathrm{a}}$ Indra Neel Pulidindi, ${ }^{\mathrm{a}}$ and
}

Aharon Gedanken ${ }^{\mathrm{a}, \mathrm{b}} *$

${ }^{a}$ Department of Chemistry, Bar-Ilan University, Ramat-Gan 52900, Israel and

${ }^{\mathrm{b}}$ Department of Materials Science and Engineering, National Cheng Kung University, Tainan 70101, Taiwan

Tel: +972-3-5318315; Fax: +972-3-7384053; *E-mail: gedanken@mail.biu.ac.il

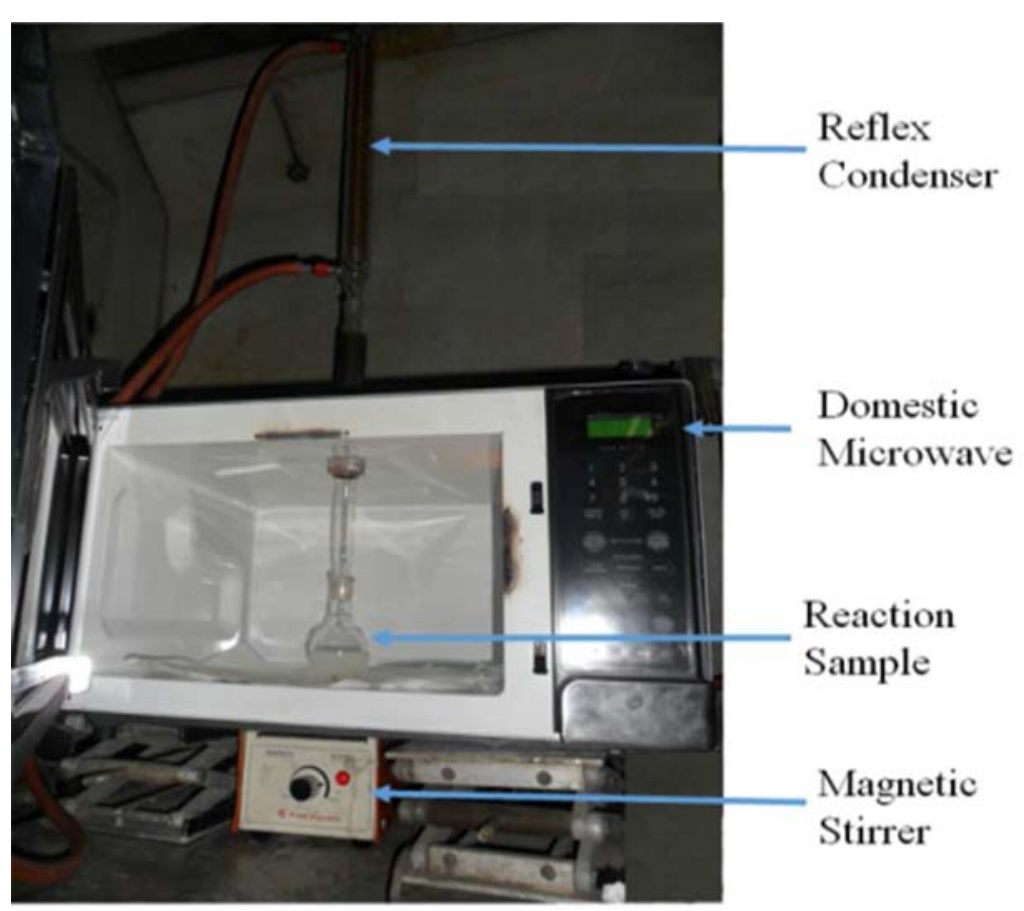

Figure S1. Modified domestic microwave oven 


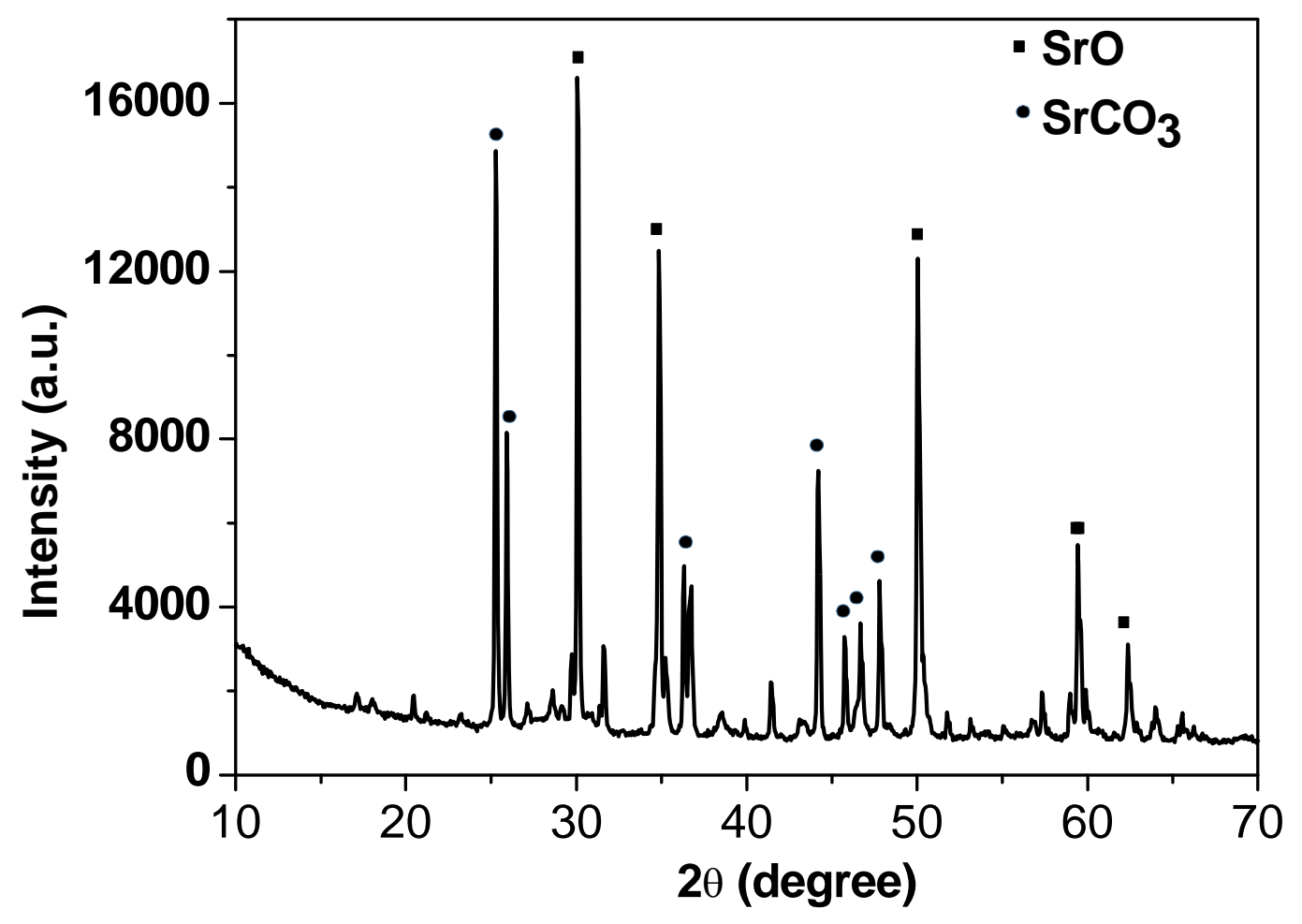

Figure S2. The XRD pattern of the material obtained after calcination of $\mathrm{SrCO}_{3} @ \mathrm{SiO}_{2}$ at $900{ }^{\circ} \mathrm{C}$ for $2 \mathrm{~h}$ in air 


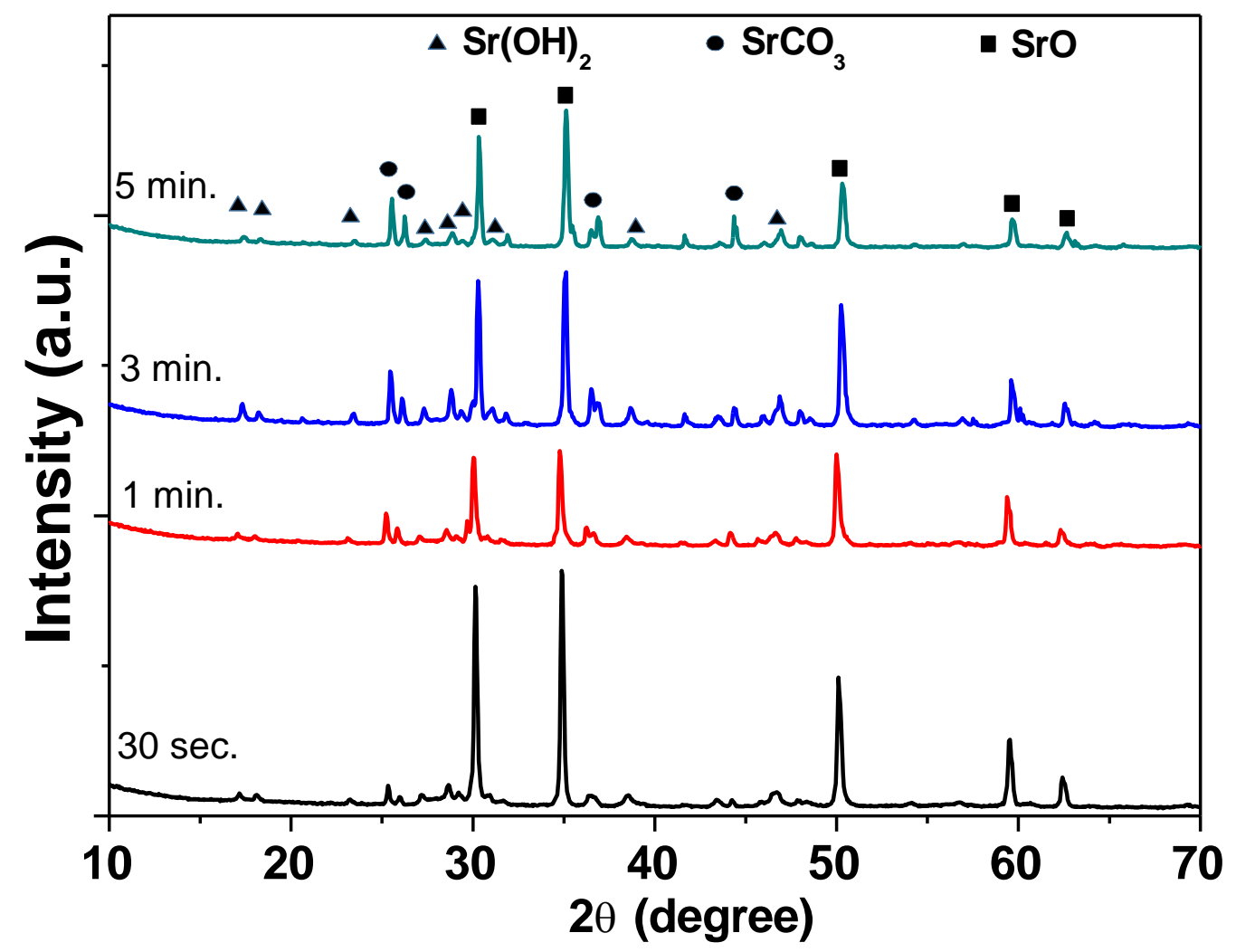

Figure S3. The effect of calcination temperature $\left(900{ }^{\circ} \mathrm{C}, 3 \mathrm{~h}\right)$ on the conversion of $\mathrm{SrCO}_{3} @ \mathrm{SiO}_{2}$ to $\mathrm{SrO} @ \mathrm{SiO}_{2}$ 


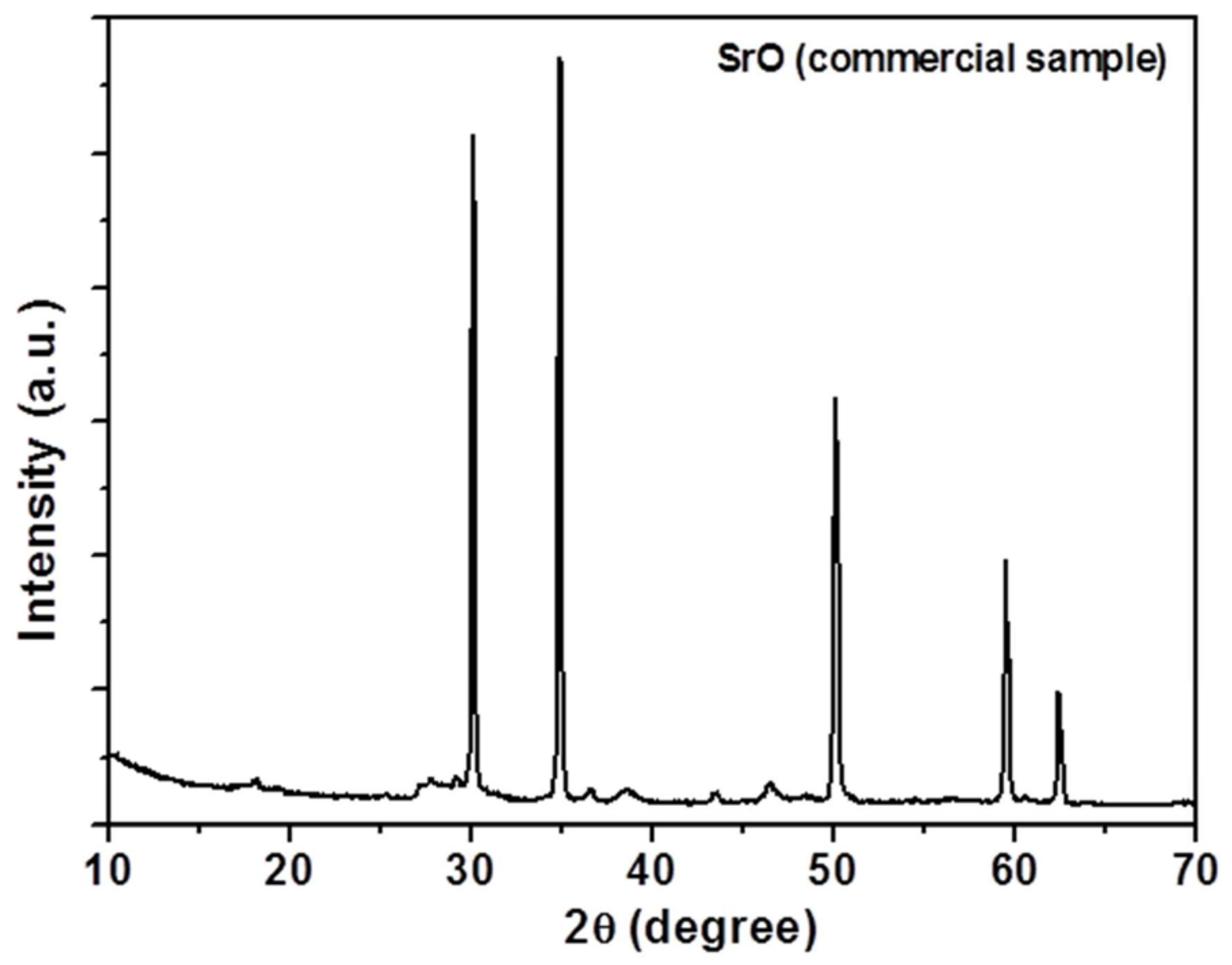

Figure S4. The XRD pattern of commercial SrO (standard) from Sigma-Aldrich 


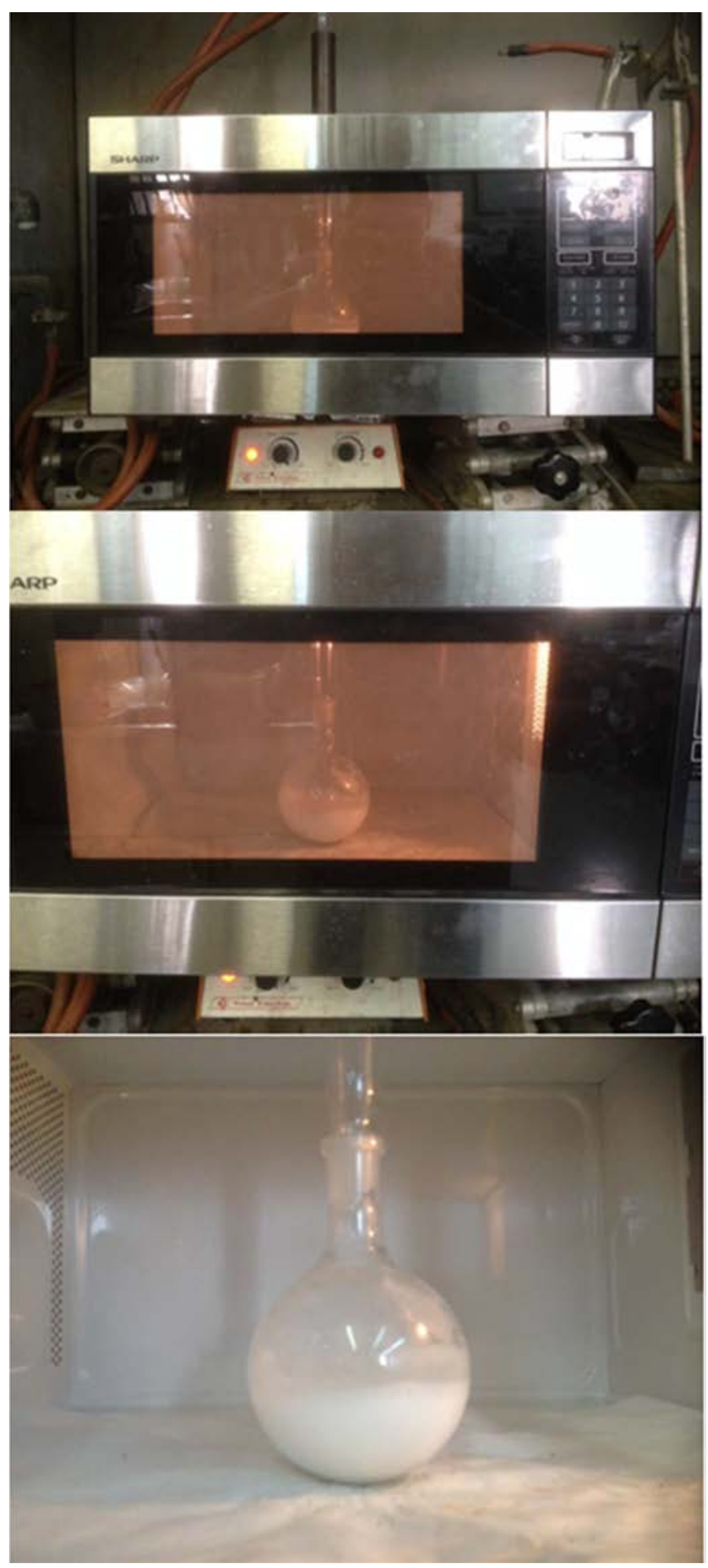

Figure S5. Pictorial representation of the catalyst $\left(\mathrm{SrO} @ \mathrm{SiO}_{2}\right)$ preparation under microwave irradiation 


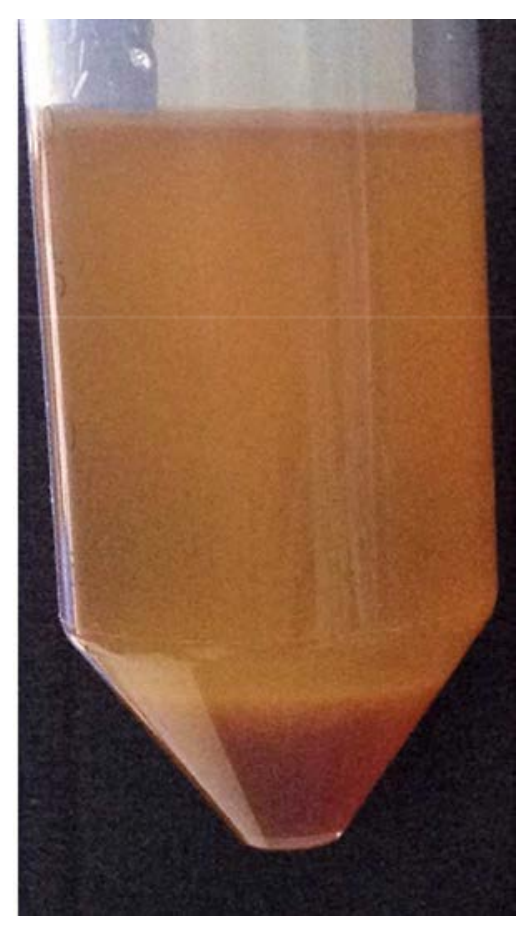

Figure S6. Product obtained from the transesterification reaction

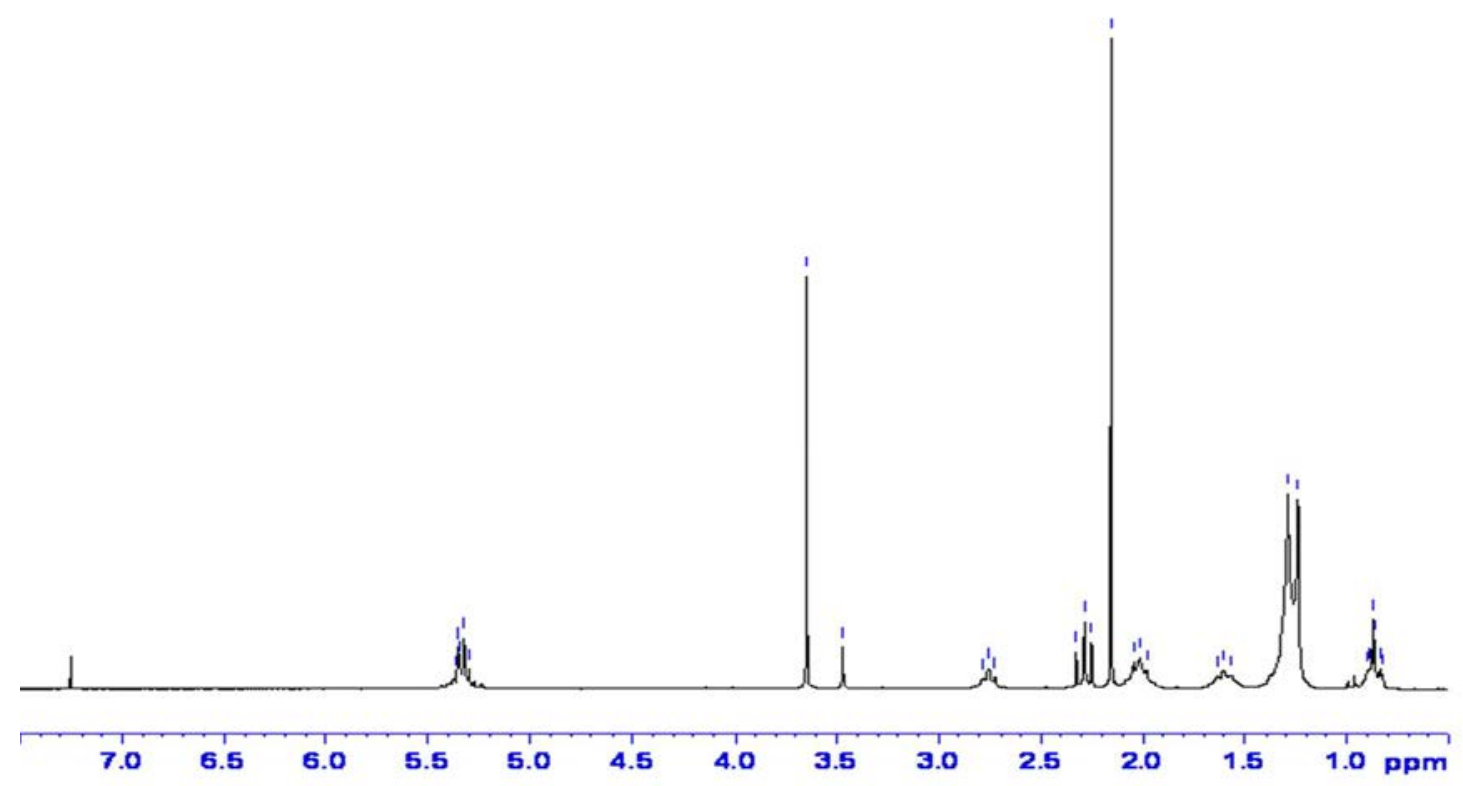

Figure S7. A typical ${ }^{1} \mathrm{H}$ NMR of FAME obtained from transesterification of cooked oil with $\mathrm{SrO@SiO} 2$ yielding 99.4 wt. \% conversion 